\title{
On Jet Impinging Boiling Heat Transfer
}

\author{
Mahmoud A. Abdelfattah and Mohamed S. Hamed ${ }^{1}$ \\ Thermal Processing Laboratory, Department of Mechanical Engineering, \\ McMaster University \\ 1280 Main Street, Hamilton, Ontario, Canada, L8S 4K1 \\ ${ }^{1}$ Corresponding Author: hamedm@mcmaster.ca
}

\begin{abstract}
Jet impingement Boiling (JIB) is an efficient means of intensive cooling. It has been utilized in many industrial applications, such as high-power electronics cooling and thermal processing of materials. Due to high heat transfer rates and rapid fluctuations in the heat flux associated with JIB, investigations carried out under controlled temperature steady-state conditions are somewhat difficult. Consequently, few research works have reported the entire boiling curve in the literature. These few studies have investigated JIB under relatively low degrees of sub-cooling. This paper presents the results of a recent investigation of JIB considering relatively high degrees of sub-cooling and jet velocity. The entire JIB curve under steady-state conditions has been obtained and compared with previously reported boiling curves. As expected, the level of sub-cooling has a significant effect on the shoulder heat flux and on the maximum rate of heat transfer.
\end{abstract}

Keywords: Jet impingement boiling, Transition boiling, Shoulder phenomena, high degree of subcooling

\section{Introduction}

Heat removal using liquid jet impingement is considered as one of the most effective cooling mechanisms in many engineering and industrial applications, such as high-power electronics cooling, thermal processing of materials and emergency cooling in nuclear reactors. Many investigations have been carried out on jet impingement boiling (JIB) covering a wide range of jet and surface conditions [1]. There are two experimental techniques commonly used to investigate JIB: transient and steady-state experiments. In transient or quenching experiments, surface temperature changes with time as the initially hot surface is subjected to the impinging jet. Although transient experiments provide enough information about the rate of heat transfer, they do not allow one to easily capture details of bubble dynamics on the surface during nucleate boiling or investigate the heat transfer mechanism in the transient boiling and film boiling. Hence transient experiments do not provide enough details of the complicated JIB phenomena necessary to understand the physics of heat transfer mechanisms associated with JIB. Such details can be attained during stead-state experiments during which surface temperature or heat flux can be maintained at a certain constant level by controlling the heat input to the surface. The entire boiling curve can be studied only if we keep the surface temperature constant. The following paragraphs summarize the few works in the literature that studied the entire JIB curve under steady-state conditions (constant surface temperature).

Robidou et al [2] performed steady-state experiments to investigate the effect of water jet velocity and degree of subcooling on the surface heat flux at the stagnation point of a free water jet impinging on a hot copper plate. They focused on the nucleate boiling and transition boiling regimes. Jet velocity and water sub-cooling varied from 0.66 to $0.8 \mathrm{~m} / \mathrm{s}$ and from 10 to $16^{\circ} \mathrm{C}$, respectively. They reported that jet velocity does not have a significant effect on the rate of heat transfer during nucleate boiling and transition boiling regimes. However, higher jet velocity resulted in a higher critical heat flux (CHF). They pointed out that their results agreed with the findings of Ma and Bergles[3] and Miyasaka et al.[4]. However it disagrees with that of Koberle and Auracher[5] who studied the nucleate boiling regime under an impinging FC-72 jet considering a wide range of jet velocity, 5 to $15 \mathrm{~m} / \mathrm{s}$.[5] found that jet velocity has an effect on the heat flux in the nucleate boiling regime. The degree of sub-cooling had a significant effect on the entire boiling curve, except nucleate boiling, where its effect was relatively weak. The reported effect of degree of sub-cooling is in good agreement with previous works reported in the literature [1].

Ahmed and Hamed [6] carried out steady-state experiments to study all boiling regimes associated with JIB. They used 
copper heated surface subjected to a planar water jet. They considered jet velocities of 0.6 and $0.75 \mathrm{~m} / \mathrm{s}$ and degree of subcooling of $15^{\circ} \mathrm{C}$.They focused on the jet stagnation region. They were able to model the heat flux in the transition regime with a mean square error of $33 \%$. However, the heating technique they used which employed a thin NiCr heating foil did not allow them to consider higher jet velocities or degrees of sub-cooling. When the flow conditions are increased that means high removal rate is extracted from the cooled surface, consequently high power should be provided to the thin foil to compensate the high cooling rate at the surface, this results in burnout of the heating foil. Induction heating could be an alternative solution for addressing such technical challenge. It has the merits of high localized heating in short time without physical contact with the copper block and fast response. It has been used by many researchers to perform steady- state boiling experiments at high rates of heat flux [7]-[9]. Hernández et al [7], [8] were able to study the entire boiling curve under steady-state conditions on a Platinum- disk subjected to water-air mist. They were able to attain high heat fluxes, up to $12 \mathrm{MW} / \mathrm{m} 2$ and high surface temperature, up to $1200^{\circ} \mathrm{C}$.

Studying JIB at steady state allows one to gain necessary and required understanding of bubble dynamics associated with JIB. This in turns allows one to develop required JIB sub-model leading to the development of a valid mechanistic JIB model. The objective of the present study is to employ induction heating technique in order to investigate the effect of relative high degrees of sub-cooling and jet velocity on the rate of heat transfer in the nucleate and transition boiling regimes under impinging water jet.

\section{Experimental Facility}

Figure 1 shows the experimental facility of the current work which is consisted of a flow loop, a heater block and a data acquisition system. A $0.5 \mathrm{HP}$ centrifugal pump is used to circulate degassed distilled water from a $60 \mathrm{~L}$ tank to the test section. The water is heated in the tank using $3 \mathrm{KW}$ thermostatic control immersion heater. The discharge line is equipped with an accumulator to prevent flow fluctuation. The flow loop is equipped with a pressure gauge to measure the flow pressure and water valve to control the water velocity. The water temperature exit from the jet is measured by a thermocouple fitted at jet inlet. The flow rate is measured by turbine flow meter. The hot water flows through a planar jet $(1 \mathrm{~mm} \times 8 \mathrm{~mm})$ and impinges the heated surface normally before collected and returned to the tank. Schematic of the heated block is shown in Figure 2. The top of the heated block is the boiling surface. The surface temperature and heat flux are determined by extrapolating temperatures measured using three thermocouples located below the boiling surface. The boiling surface has the dimensions of $8 \times 10 \mathrm{~mm} 2$ and insulated with machinable ceramic, two pieces of high transparent acrylic are used to confine the flow. The surface was polished by grit paper Silicone Carbide 1200/4000. Three K-type thermocouples of 0.5 $\mathrm{mm}$ in diameter are used to measure the temperature distribution in the copper heater at the stagnation zone. The thermocouples were inserted to halfway of the block $(4 \mathrm{~mm})$ fitted in the holes with high temperature thermal paste. The temperature measurements were acquired by Keithly DAQ model 2700 with sample rate of 0.2 samples per second. All thermocouples were calibrated using RTD, the maximum deviation in temperature readings was $0.46^{\circ} \mathrm{C}$. The induction system consists of power supply unit model VERSAPOWER $5 \mathrm{KW}$ nominal power and output heat section that connected to induction coil encasing the heater block. The coil can hold up to 200A/350V, chilled water passes through the coil to prevent the coil from overheating. The power supply is connected to a control box (24V/10A) with a PID controller which adjusts the power supplied to the induction coil to keep the boiling surface at constant temperature. The experimental matrix for the current work is shown in Table 1.

\section{Data Reduction}

To calculate the heat flux from the surface at the stagnation point, one dimensional analysis was assumed. The heat flux can be calculated by Eq. (1).

$$
q_{s}^{\prime \prime}=\left.k_{c u} \frac{\partial T}{\partial y}\right|_{y=0}
$$

Where, $k_{c u}$ is copper thermal conductivity, which was taken as $380 \mathrm{~W} / \mathrm{m} . \mathrm{K}$. The maximum uncertainty of the heat flux, surface temperature are $9 \%$ and $0.4 \%$, respectively. 


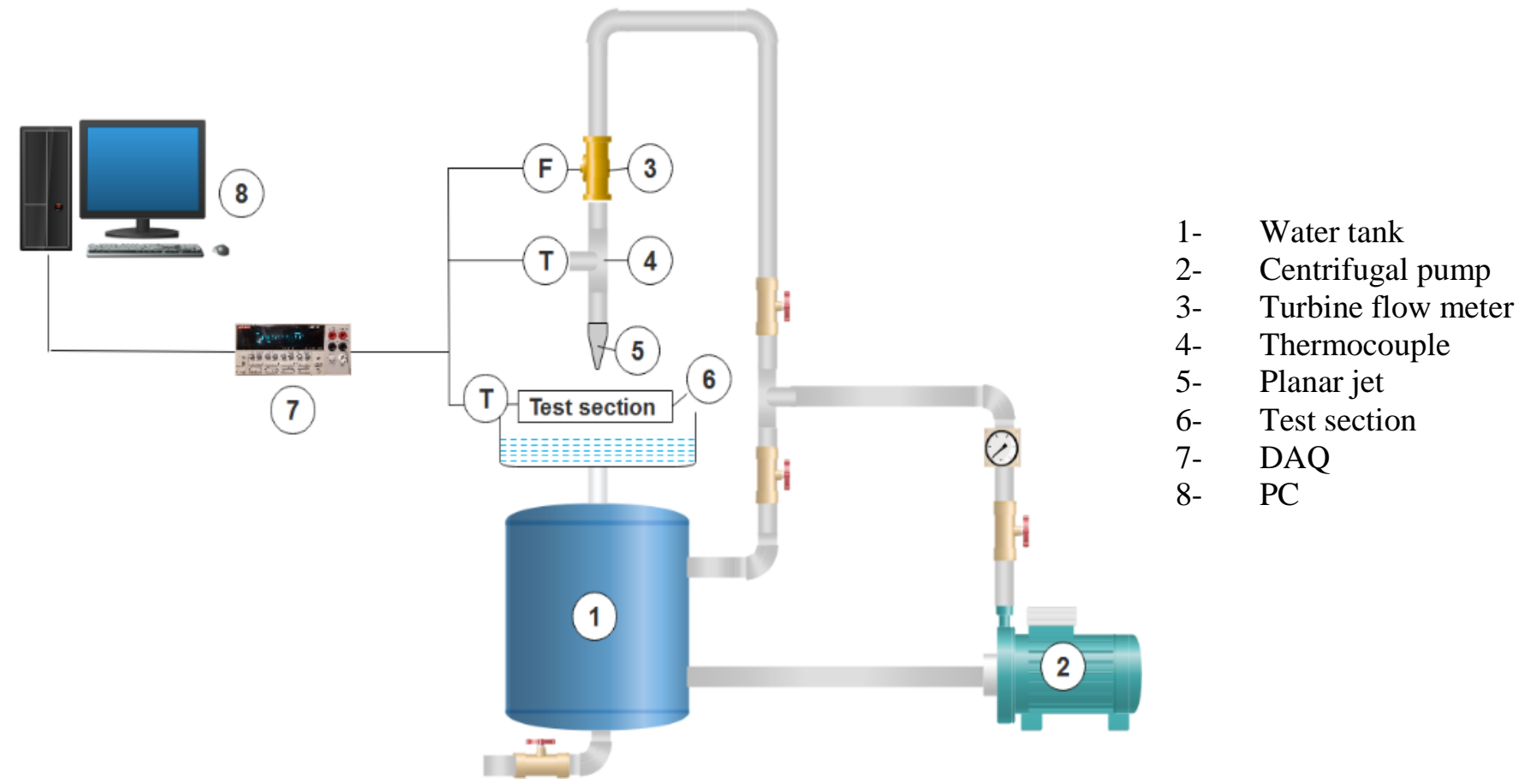

Figure 1: Layout of experimental setup.

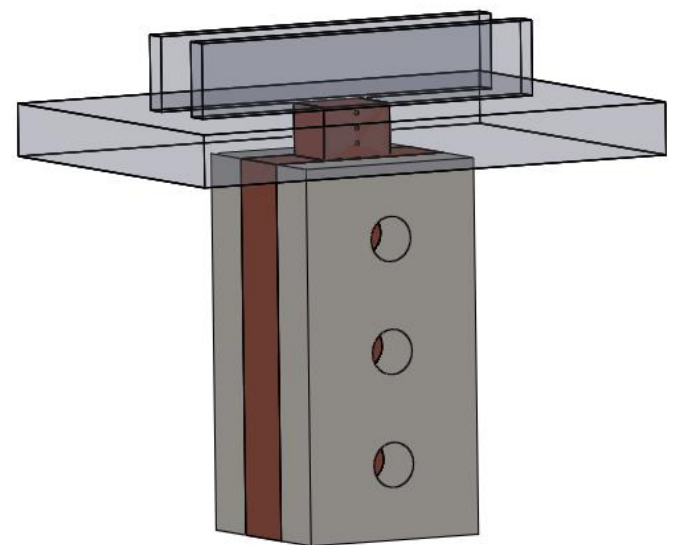

Figure 2: Schematic of the heater block.

Table 1: Matrix of experiments.

\begin{tabular}{|l|l|}
\hline Jet velocity & Liquid subcooling \\
\hline $1 \mathrm{~m} / \mathrm{s}$ & $10^{\circ} \mathrm{C}, 18^{\circ} \mathrm{C}$, and $36^{\circ} \mathrm{C}$ \\
\hline $2 \mathrm{~m} / \mathrm{s}$ & $10^{\circ} \mathrm{C}$ and $18^{\circ} \mathrm{C}$ \\
\hline
\end{tabular}

\section{Results and Discussion}

In this section results of steady-state, experiments are presented. The effect of jet velocity and liquid subcooling on the boiling curve are discussed in sections 1 and 2, respectively. The boiling curve produced by using the current experimental setup is in good agreement with boiling curves reported in the literature[2], [6], as shown in Figure 3. However, the CHF in the current work is slightly lower compared to previous works due to the lower degree of sub-cooling. 


\subsection{Effect Of Jet Velocity}

Figure 4 and Figure 5 show the influence of changing jet velocity from $1 \mathrm{~m} / \mathrm{s}$ to $2 \mathrm{~m} / \mathrm{s}$ on the boiling curve at liquid subcooling $10^{\circ} \mathrm{C}$ and $18^{\circ} \mathrm{C}$, respectively. It can be noticed that jet velocity increase has an insignificant effect on the heat flux in the nucleate boiling regime at liquid subcooling of $10^{\circ} \mathrm{C}$, as shown in Figure 4, while the boiling curve in nucleate regime is shifted up and to the right slightly at liquid subcooling of $18^{\circ} \mathrm{C}$, as shown in Figure 5 this agrees with the results reported in [10]. This is might be due to the small thickness of thermal and momentum boundary layers that delay boiling incipience as bubble growth is suppressed by jet momentum and cold bulk liquid. The critical heat flux (CHF) increased noticeably by increasing jet velocity as jet momentum breaks the large vapor bubbles which prevent liquid from reaching the hot surface and form an insulative vapor blanket that diminishes the heat transfer. Its value increased from $3 \mathrm{MW} / \mathrm{m} 2$ to 4.2 MW/m2 at liquid subcooling of $10^{\circ} \mathrm{C}$ and from $6.2 \mathrm{MW} / \mathrm{m} 2$ to $7.5 \mathrm{MW} / \mathrm{m} 2$ at liquid subcooling of $18^{\circ} \mathrm{C}$. In the transition regime, the shoulder phenomena exist for all cases. This phenomenon is attributed to the breakup and formation of vapor pockets on the heated surface. The breakup of large bubbles into micro bubbles enhances the fluid mixing, hence results in an increase in the wettability of the surface [6], [11]. One can notice that the heat flux in the transition regime increases beyond the CHF value except for subcooling temperature of $10^{\circ} \mathrm{C}$ at low velocity $1 \mathrm{~m} / \mathrm{s}$ where the heat flux value is lower than the CHF value, as shown in Figure 4. The effect of jet velocity and liquid subcooling on the mechanism of heat transfer in this regime is not well understood and needs more investigation.

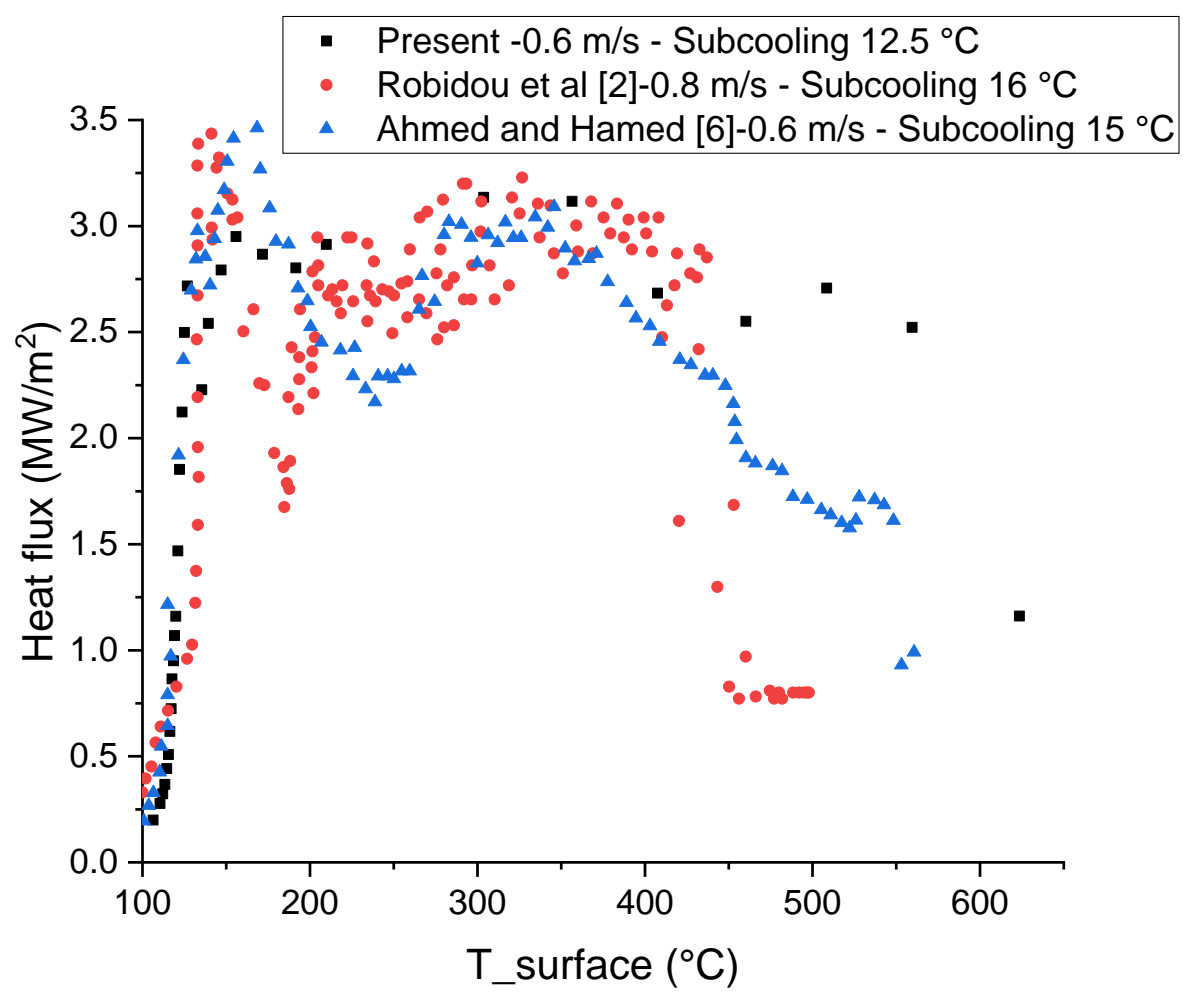

Figure 3: Comparison between the current and previous boiling curves 


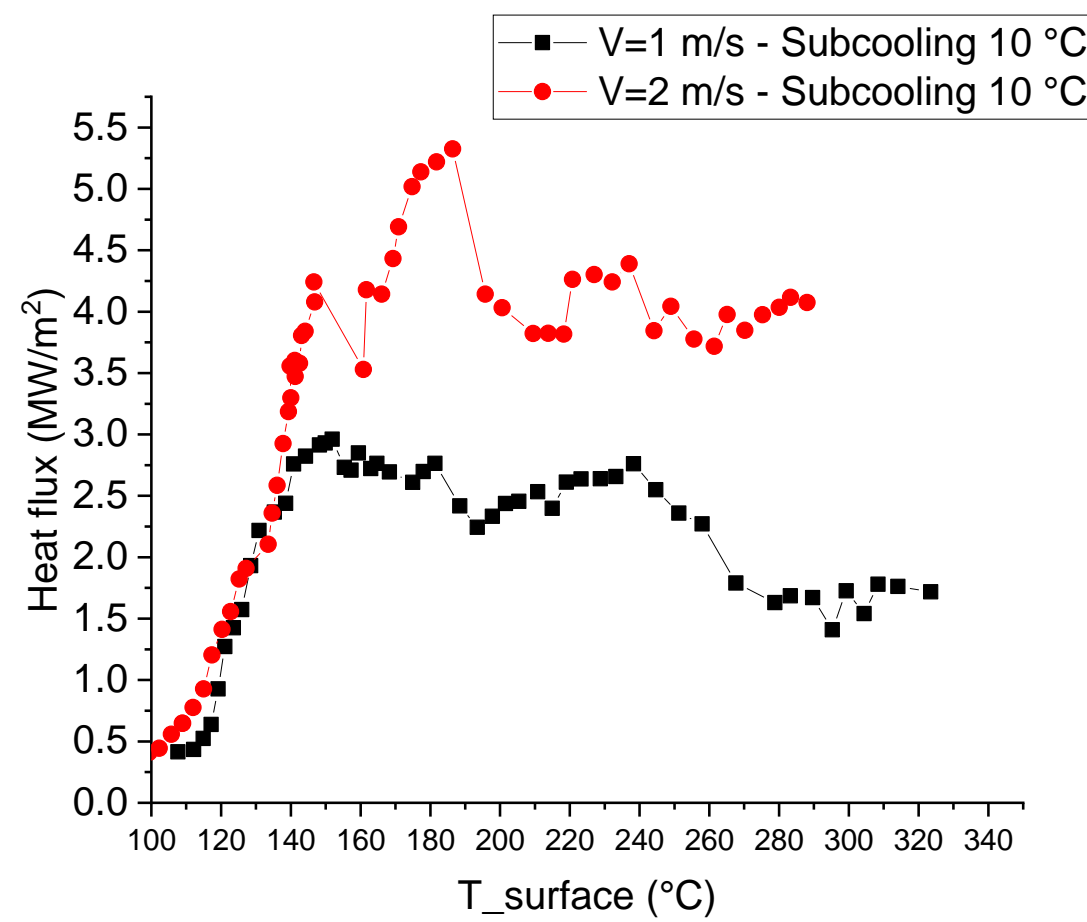

Figure 4: Effect of jet velocity on boiling curve at water sub-cooling of $10^{\circ} \mathrm{C}$.

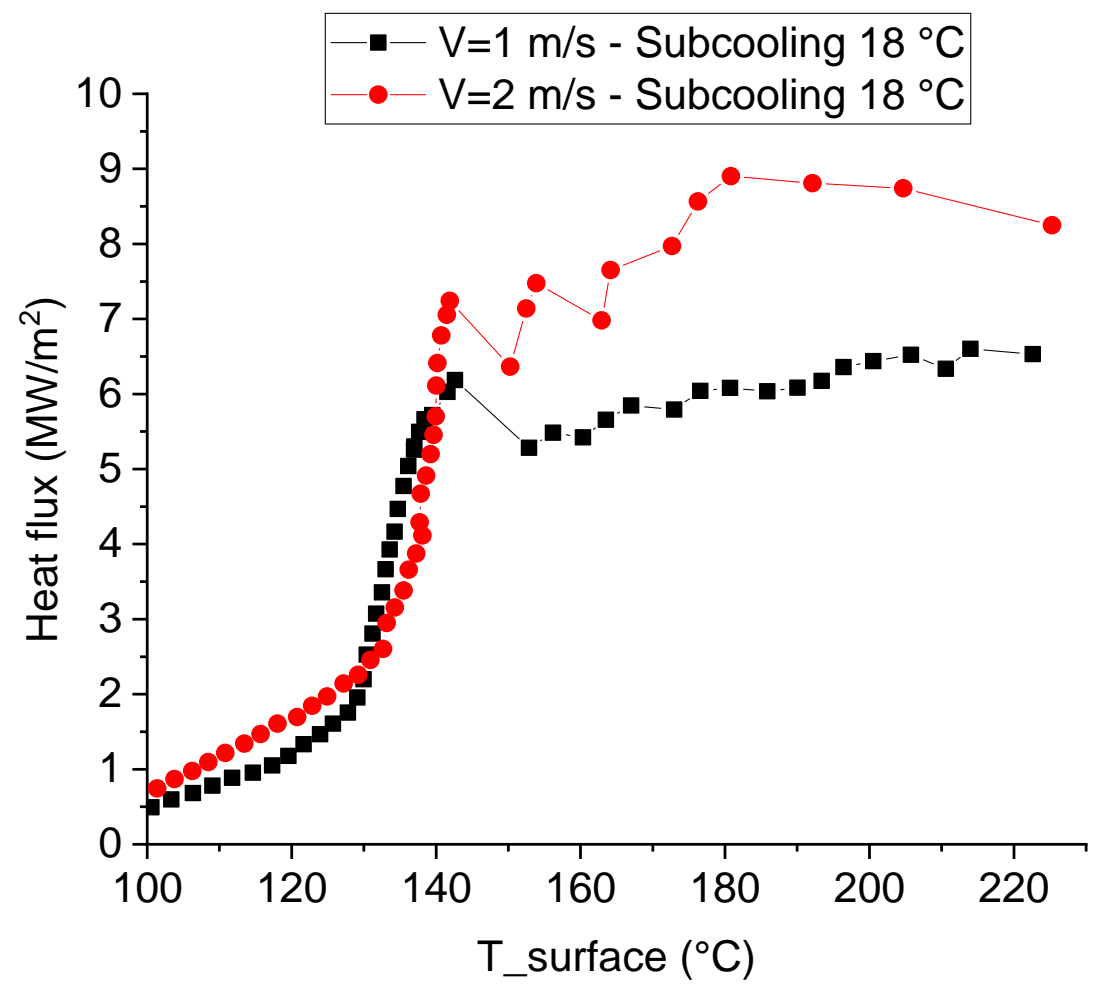

Figure 5: Effect of jet velocity boiling curve at water sub-cooling of $18^{\circ} \mathrm{C}$. 


\subsection{Effect Of Liquid Sub-Cooling}

The effect of liquid sub-cooling on the boiling curve obtained at jet velocity of $1 \mathrm{~m} / \mathrm{s}$ and $2 \mathrm{~m} / \mathrm{s}$ is depicted in Figure 6 and 7, respectively. In general, the liquid sub-cooling has a significant effect on the convection, the CHF and the shoulder heat flux. Although the effect on nucleate regime was found to be weak at jet velocity of $1 \mathrm{~m} / \mathrm{s}$, the boiling curve shifted up with subcooling increase at jet velocity of $2 \mathrm{~m} / \mathrm{s}$. At jet velocity of $1 \mathrm{~m} / \mathrm{s}$, The CHF increased almost twice (from 3 to 6.2 $\mathrm{MW} / \mathrm{m} 2$ ) by increasing the liquid subcooling from $10^{\circ} \mathrm{C}$ to $18^{\circ} \mathrm{C}$. The same trend is noticed at jet velocity of $2 \mathrm{~m} / \mathrm{s}$ where The CHF increased from 4.2 to $7.2 \mathrm{MW} / \mathrm{m} 2$ which represents $70 \%$ increase. Figure 6 shows the boiling curve at jet velocity of $1 \mathrm{~m} / \mathrm{s}$ and different liquid subcooling (i.e., $10^{\circ} \mathrm{C}, 18^{\circ} \mathrm{C}$, and $36^{\circ} \mathrm{C}$ ). The $\mathrm{CHF}$ increased by $100 \%(3$ to $6.2 \mathrm{MW} / \mathrm{m} 2)$ and $166 \%$ ( 3 to $8 \mathrm{MW} / \mathrm{m} 2$ ) when the liquid subcooling increased by $80 \%$ and $260 \%$, respectively. It can be noticed that the percentage increase is not linear with subcooling increase. Although jet velocity affects the CHF and shoulder heat flux positively, the effect of liquid subcooling is found to be more dominant than that of jet velocity. These results agree with the literature [1] where the CHF is proportional to $V^{1 / 3}$ and $\Delta T_{\text {sub }}^{n}$ where $\mathrm{n}=1.4-2.0$.

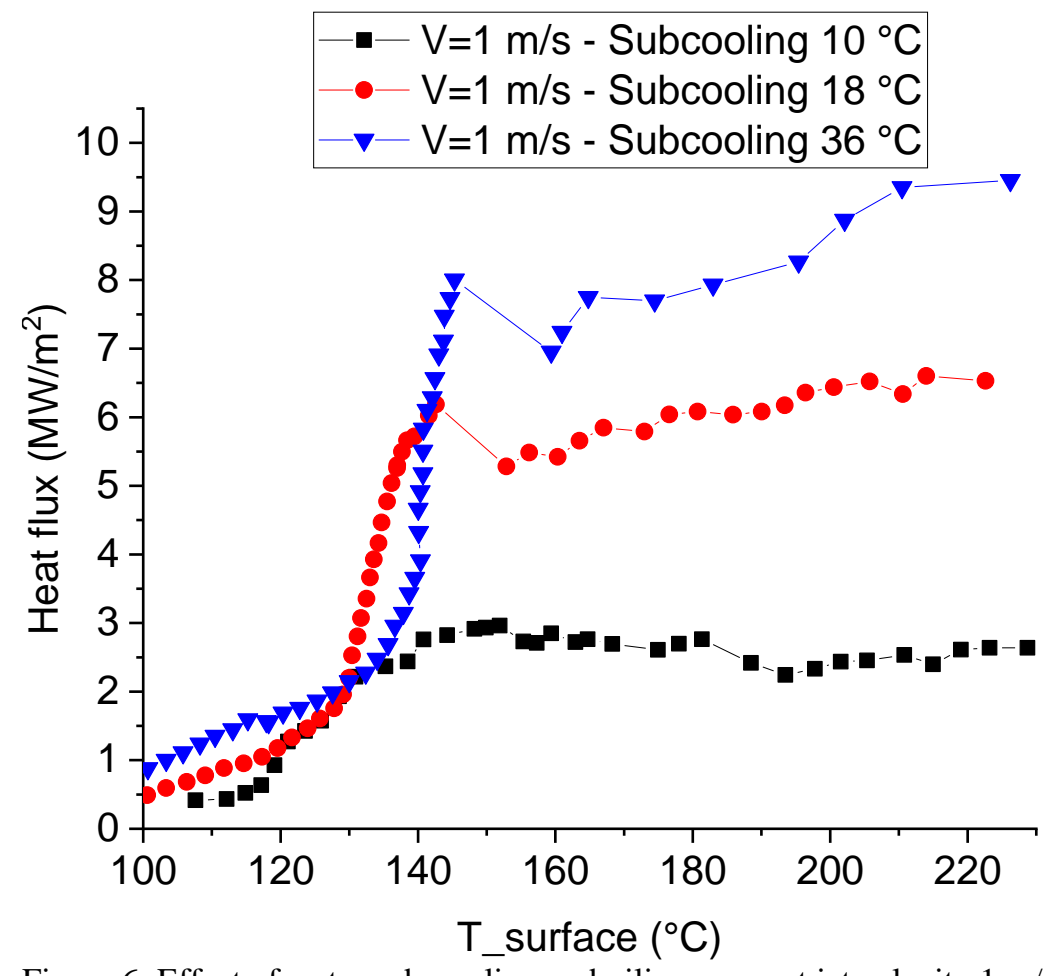

Figure 6: Effect of water sub-cooling on boiling curve at jet velocity $1 \mathrm{~m} / \mathrm{s}$. 


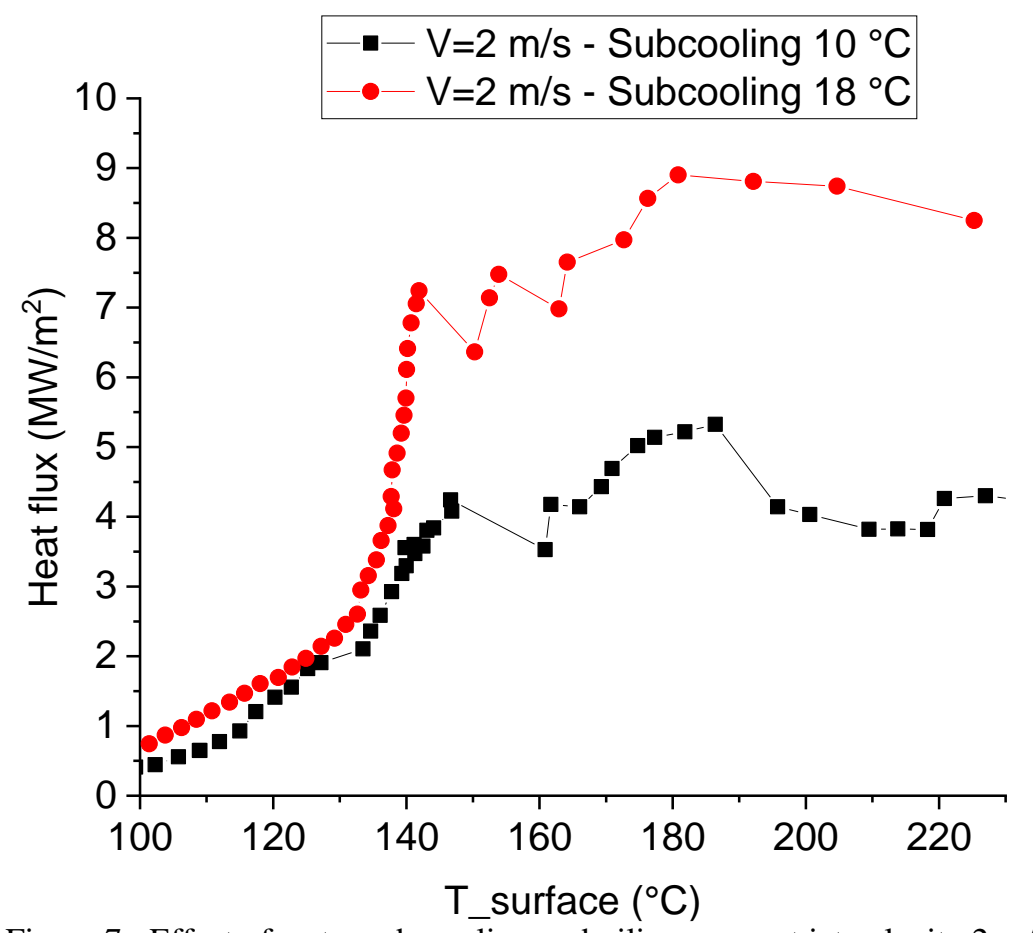

\section{Conclusions}

An induction heating system has been used to carry out a set of steady-state experiments under constant surface temperature to study the effect the jet boiling curve at relative higher liquid sub-cooling and jet velocity than that available in the literature. Studying the JIB at steady state constant surface temperature at high heat flux is important so that one is able to study the bubble dynamics at high degree of sub-cooling and jet velocity in the nucleate regime and understand the heat transfer mechanism in the transition regime. Based on the results, one can conclude the following:

1. The effect of jet velocity on heat removal rate in the nucleate boiling regime has found to be insignificant.

2. Although increasing jet velocity results in an improvement of the CHF and heat flux in the transition regime, this improvement decreases at high sub-cooling.

3. The heat transfer improvement in the transition regime and CHF due to liquid subcooling increase was found to be more significant than that of jet velocity.

\section{Acknowledgment}

The authors would like to acknowledge financial support received from the Natural Sciences and Engineering Research Council of Canada (NSERC).

\section{References}

[1] D. H. Wolf, F. P. Incropera, and R. Viskanta, "Jet impingement boiling," in Advances in heat transfer, vol. 23, Elsevier, 1993, pp. 1-132.

[2] H. Robidou, H. Auracher, P. Gardin, and M. Lebouché, "Controlled cooling of a hot plate with a water jet," Exp. Therm. Fluid Sci., vol. 26, no. 2-4, pp. 123-129, 2002.

[3] C.-F. Ma and A. E. Bergles, "Jet impingement nucleate boiling," Int. J. Heat Mass Transf., vol. 29, no. 8, pp. 1095$1101,1986$.

[4] Y. Miyasaka, S. Inada, and Y. Owase, "Critical heat flux and subcooled nucleate boiling in transient region between a two-dimensional water jet and a heated surface," J. Chem. Eng. Japan, vol. 13, no. 1, pp. 29-35, 1980. 
[5] K. Köberle and H. Auracher, "Temperature controlled measurements of the critical heat flux on microelectronic heat sources in natural convection and jet impingement cooling," in Thermal Management of Electronic Systems, Springer, 1994, pp. 233-242.

[6] A. B. Ahmed and M. S. Hamed, "Modeling of transition boiling under an impinging water jet," Int. J. Heat Mass Transf., vol. 91, pp. 1273-1282, 2015.

[7] C. A. Hernández-Bocanegra, F. A. Acosta-González, X. Zhou, and B. G. Thomas, "Measurement of heat flux in dense air-mist cooling: Part I-A novel steady-state technique," Exp. Therm. Fluid Sci., vol. 44, pp. 147-160, 2013.

[8] C. A. Hernández-Bocanegra, J. I. Minchaca-Mojica, F. A. Acosta-González, X. Zhou, and B. G. Thomas, "Measurement of heat flux in dense air-mist cooling: Part II-The influence of mist characteristics on steady-state heat transfer," Exp. Therm. Fluid Sci., vol. 44, pp. 161-173, 2013.

[9] S. Hua, R. Huang, Z. Li, and P. Zhou, "Experimental study on the heat transfer characteristics of subcooled flow boiling with cast iron heating surface," Appl. Therm. Eng., vol. 77, pp. 180-191, 2015.

[10] A. M. T. Omar, M. S. Hamed, and M. Shoukri, "Nucleate boiling heat transfer under liquid jet impingement," in ASME/JSME 2007 Thermal Engineering Heat Transfer Summer Conference collocated with the ASME 2007 InterPACK Conference, 2007, pp. 723-729.

[11] L. Bogdanic, H. Auracher, and F. Ziegler, "Two-phase structure above hot surfaces in jet impingement boiling," Heat mass Transf., vol. 45, no. 7, pp. 1019-1028, 2009. 